This manuscript has been submitted for publication in Geophysical Research Letters. Subsequent versions of this manuscript may have slightly different content. If accepted, the final version of this manuscript will be available via the 'Peer-reviewed Publication DOI' link on the right-hand side of this webpage. Please feel free to contact any of the authors; we welcome feedback.

\title{
Small-scale capillary heterogeneity linked to rapid plume migration during $\mathrm{CO}_{2}$ storage
}

\author{
S. J. Jackson ${ }^{1,2}$, S. Krevor ${ }^{1}$ \\ ${ }^{1}$ CSIRO Energy, Clayton South, Victoria, Australia
${ }^{2}$ Imperial College London, Department of Earth Science \& Engineering, London, U.K.
}

\section{Key Points:}

- Core-to-field multiscale experiments, modelling, and upscaling elucidate the impacts of small-scale heterogeneity on subsurface $\mathrm{CO}_{2}$ storage.

- dm-m scale layered capillary heterogeneities can cause rapid field-scale plume migration, $100-200 \%$ faster than homogeneous \& isotropic cases.

- Capillary heterogeneity places leading order controls on plume migration, and could contribute to unexpected $\mathrm{CO}_{2}$ migration seen worldwide.

\begin{abstract}
Unpredicted, rapid plume elongation has been observed at subsurface $\mathrm{CO}_{2}$ storage projects worldwide, exemplified by the Sleipner project. We show that conventionally ignored centimetre-metre scale heterogeneity in capillary pressure characteristics can manifest as rapid field-scale, decametre-kilometre, plume migration. We analyse the effect in the Goldeneye Field, UK, a proposed storage site with a unique combination of sample/data accessibility and generality as an archetype sandstone reservoir. We overcome previous barriers by characterising in greater detail over larger scales - the $65 \mathrm{~m}$ reservoir height at $\mathrm{cm}-\mathrm{m}$ resolution - and through use of an upscaling scheme which resolves small-scale heterogeneity impacts in field-scale simulations. These models reveal that significant early time retardation of buoyantly rising $\mathrm{CO}_{2}$ plumes is followed by rapid migration under the caprock in the presence of anisotropic, layered heterogeneities. Lateral migration speeds can be enhanced by $200 \%$, placing first order controls on fluid flow and providing a mechanistic explanation for field observations.
\end{abstract}

\section{Plain Language Summary}

Geological carbon storage is a promising technique to reduce greenhouse gas emissions. Captured carbon dioxide is generally injected into a subsurface reservoir over $1000 \mathrm{~m}$

Corresponding author: S. J. Jackson, samuel.jackson@csiro.au 
underground, displacing resident brine and eventually becoming trapped underneath a lowpermeability caprock seal. However, at several industrial scale storage sites around the world, the carbon dioxide has migrated laterally away from the injection well much quicker than anticipated, and followed pathways that are not predicted by models. It is crucial that these models can predict the migration and demonstrate safe storage to owners and policy makers. In this work, we show that one source of the discrepancy is the omission of the impacts of small-scale rock heterogeneities in these models. We experimentally characterise rock cores from a North Sea reservoir at high-resolution, and through rigorous multi-scale modelling show that centimetre-metre scale heterogeneities in the rock structure, e.g. small mudstone layers in sandstone, can cause rapid migration at larger, metre-kilometre scales. Carbon dioxide can migrate up to $200 \%$ faster in the presence of layered heterogeneities. These heterogeneities are ubiquitous in nature, and provide an explanation for the behaviour seen at storage sites worldwide. Our modelling approach incorporates this behaviour, improving the predictability and control of storage operations.

\section{Introduction}

$\mathrm{CO}_{2}$ plume migration remains difficult to accurately simulate and predict at industrial scale, subsurface storage projects. Plume elongation and early breakthrough at monitoring wells has occurred at a number of projects of various sizes, see Figure 1a. This includes Sleipner, North Sea, Norway (Chadwick et al., 2009; G. Williams \& Chadwick, 2012); In Salah, Algeria (Ringrose et al., 2013); Frio stage I and II projects, Texas, USA (Hovorka et al., 2006; Daley et al., 2011); Cranfield, Mississippi, USA (Hosseini et al., 2013); and the Otway stage 2 project, Otway, Victoria, Australia (Dance et al., 2019). In all of these examples, the seismically imaged $\mathrm{CO}_{2}$ plume has extended laterally away from injection points along pathways and at rates neither predicted nor easily matched by conventional approaches to reservoir simulation. The Quest project in Alberta, Canada, provides a notable exception where lateral plume migration is significantly less than anticipated from prior modelling (Halladay et al., 2018).

A number of hypotheses have been proposed to explain the unexpected behaviour. Most frequently studies invoke the existence of a high permeability channel or fracture, aligned with the flow direction (G. Williams et al., 2018; Cowton et al., 2018; Ringrose et al., 2013; Dance et al., 2019). When combined with varying caprock topography, this can place a leading order control on the migration pathway (Gasda et al., 2013; Nilsen et al., 2017; Cowton et al., 2018). Thermal effects and the uncertainty in the fluids' thermophysical properties (including contamination) have also been suggested as an underlying cause (G. A. Williams \& Chadwick, 2017; Hodneland et al., 2019). Even accounting for the large uncertainties in subsurface system properties, precise matches to plume behaviour have only been achieved using model parameters, e.g., permeability, outside the range of values constrained by observations.

This difficulty suggests a gap in the physics represented in the models used to simulate flow behaviour. A number of studies have demonstrated an important control of smallscale heterogeneities in capillary pressure characteristics giving rise to upscaled impacts on multiphase flow (Yeh et al., 1985; Ferrand \& Celia, 1992; Saadatpoor et al., 2010; Cavanagh \& Haszeldine, 2014; B. Li \& Benson, 2015; Gershenzon et al., 2015; Park et al., 2016; Trevisan, Krishnamurthy, \& Meckel, 2017; Braun et al., 2005). In the current context, we consider small-scale heterogeneities as lenses, laminae or bedding heterogeneities ranging from $0.1 \mathrm{~m}$ to several metres in thickness (Ringrose et al., 1993; Gershenzon et al., 2014), which are at least an order of magnitude smaller than the plume migration. In application to $\mathrm{CO}_{2}$ storage, the impacts have been shown to play a significant role in inhibiting the upward migration of injected $\mathrm{CO}_{2}$, and in the enhancement of trapping. Past work on nonaqueous phase liquid (NAPL) contamination has shown that these heterogeneities can also result in significant enhancements in lateral migration; with NAPL, this can occur with a sinking dense contaminant plume (Braun et al., 2005). This impact on lateral migration 
is unexplored for $\mathrm{CO}_{2}$ storage and is the focus of this work. Moreover, the evaluation of the fine-scale controls of multiphase flow heterogeneity have been limited by both a lack of the high spatial resolution petrophysical data from field locations required to constrain such hypotheses, and the implementation of upscaling approaches that honour the impacts of these properties at field scales. In this work we combine laboratory characterisation of a case study reservoir with a rigorous multi scale upscaling approach.

We show that the impact of small, dm-m scale, heterogeneity in capillary pressure characteristics, can manifest as rapid field-scale, decametre to kilometre, plume migration. We overcome previous gaps by addressing issues of both characterisation and modelling. We perform a high spatial resolution laboratory characterisation of the entire $65 \mathrm{~m}$ height of a target $\mathrm{CO}_{2}$ storage site, the Goldeneye Field in the Captain Sandstone of the UK Central North Sea (Shell U. K. Limited, 2015). This is then used in the creation of numerical models in an upscaling workflow that allows us to evaluate the kilometre-scale impacts of the fine-scale heterogeneity in a model of the Goldeneye field.

\section{Scaling analysis for small-scale heterogeneities}

First we demonstrate the general prevalence of the impacts of small-scale heterogeneities by consideration of the forces driving fluid flow. Subsurface $\mathrm{CO}_{2}$ migration is driven by gradients in fluid pressure, capillary pressure $\left(P_{c}=P_{C O_{2}}-P_{w}\right)$ and buoyancy (Zhou et al., 1994). Conventional scaling analysis of these potentials identifies that the vis-

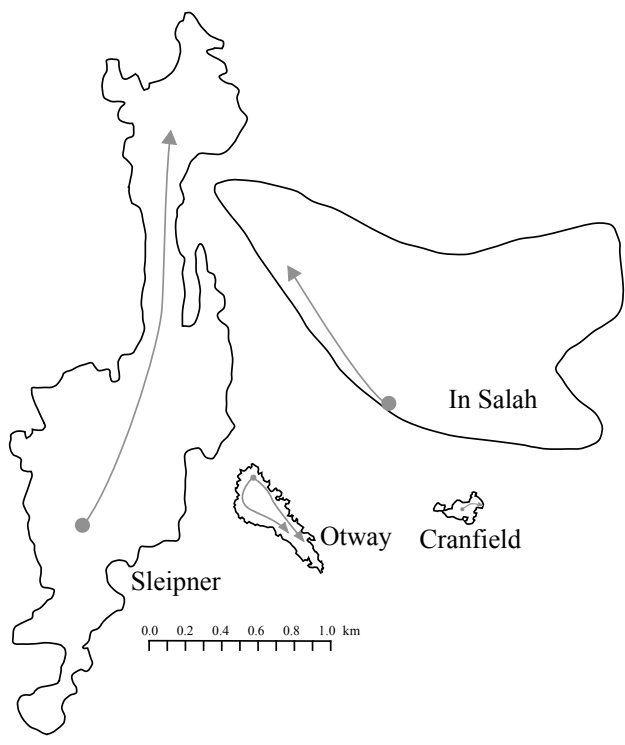

(a)

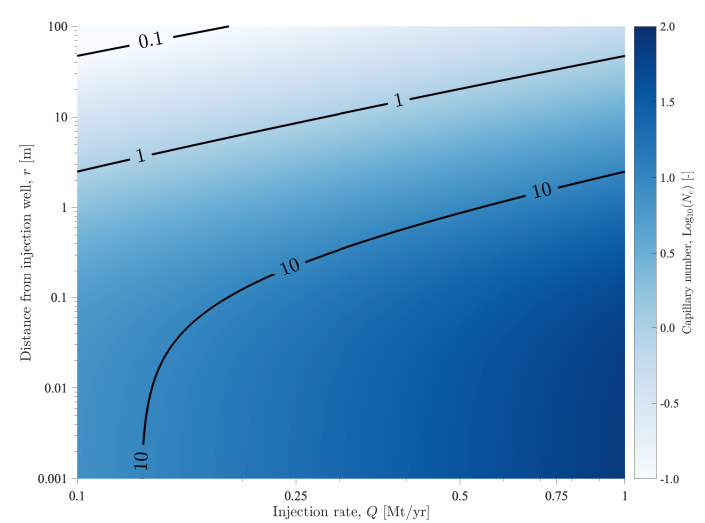

(b)

Figure 1. (a) Footprints of $\mathrm{CO}_{2}$ plumes observed at injection projects with unexpected migration pathways. Arrows show the direction of the unexpected and difficult to model migration paths (Cowton et al., 2016; Ringrose et al., 2009; Dance et al., 2019; Hosseini et al., 2013). (b) Field-scale capillary numbers associated with a highly permeable aquifer (i.e. typical of the Darcy magnitude permeability of the formations at Sleipner, Otway, Frio and Quest) as a function of injection rate and radial distance from the injection well. In this conservative example, capillary equilibrium $\left(N_{c}\right.$ $<1)$ is established after a radial distance of $47 \mathrm{~m}(\mathrm{Q}=1 \mathrm{Mt} / \mathrm{yr}), 21 \mathrm{~m}(\mathrm{Q}=0.5 \mathrm{Mt} / \mathrm{yr})$ and $8.7 \mathrm{~m}$ $(\mathrm{Q}=0.25 \mathrm{Mt} / \mathrm{yr})$ respectively, over a $1 \mathrm{~m}$ capillary heterogeneity of magnitude $\Delta P_{c}=5 \mathrm{kPa}$. Further parameters used for the calculation are detailed in the Supporting Information (SI). 
cous or buoyant terms dominate at spatial scales of order $1 \mathrm{~m}$ and greater. Capillary pressure gradients can be ignored over field scales because they contribute little to fluid movement (Zhou et al., 1994; Bear, 1989).

This approach overlooks a key impact that small-scale heterogeneity in capillary pressure characteristics can have on large-scale plume migration. The establishment of equilibrium in capillary pressure over small length scales in heterogeneous rocks has a significant impact on the local fluid mobility. As has been identified previously, trapping will be significantly enhanced with fluid flow across layers (Saadatpoor et al., 2010; Krevor et al., 2011; Meckel et al., 2015). However, average relative permeability can also be dramatically enhanced in flow parallel to layers across which capillary heterogeneity has been established (see (Virnovsky et al., 2004) for numerical simulations and (Reynolds \& Krevor, 2015) for experimental observations).

We illustrate the prevalence of the state of local capillary equilibrium with a simple scaling argument. A dimensionless capillary number, $N_{c}$, represents the ratio of viscous to capillary forces. We use the number proposed by (Virnovsky et al., 2004), $N_{c}=\frac{H \Delta P}{L \Delta P_{c}}$, but the discussion applies using equivalent numbers proposed by others, e.g., (Zhou et al., 1994). There are two key spatial scales. The flow length $L$ is the path length along which fluid is driven by buoyancy or gradients in pressure, $\Delta P$. Secondly, the spatial scale $H$ is the length scale characteristic of a heterogeneity, e.g., the thickness of a bedform layer in sandstone. This length scale is limited to the distances, approximately meters or less, over which fluid distribution by capillary forces is approximately linear with respect to the gradient in capillary pressure. Capillary equilibrium is established when gradients in capillary pressure, $\Delta P_{c}$, equalise across heterogeneities. The flow path length, $L$, at which the capillary number $N_{c}<1$ indicates the distance of fluid travel, e.g., away from an injection point, beyond which capillary equilibrium across heterogeneities has been established. This is the point at which enhancements to fluid mobility and trapping due to heterogeneity will prevail.

Approximations of these length scales for existing injection sites shows that capillary equilibrium is generally established within several meters of a $\mathrm{CO}_{2}$ injection well. This is due largely to the radial nature of the injection, meaning the driving pressure decays logarithmically away from the source; even in the strongest injection settings, capillary heterogeneities will eventually prevail. Figure 1 provides the estimated equilibrium length scale (in this case the radial distance, $r$, is used, that is $L=r$ ) for varying injection rates for an archetype, highly permeable aquifer, analogous to the Darcy magnitude sandstones at Sleipner, Frio, Quest and Otway, with calculation details in the SI. This example is conservative, with lower permeability, stronger heterogeneity contrast cases (e.g. In Salah and Cranfield) likely to equilibrate within shorter distances.

Thus it is a general feature of subsurface $\mathrm{CO}_{2}$ migration over large scales that it is characterised by flow where the fluid distribution is in capillary equilibrium across heterogeneities up to meters in dimension. Fluid mobility (e.g., $K k_{r} / \mu$ ) will therefore be largely controlled by the nature of small-scale heterogeneities in multiphase flow properties; flow along layers will have enhanced mobility, whilst flow against layers will have reduced mobility and increased trapping. In the following sections we evaluate the quantitative impact these small heterogeneities have on plume migration away from injection points.

\section{The impact of small-scale heterogeneities on lateral plume migration}

We now evaluate the impacts of capillary equilibrium across small-scale heterogeneities on lateral plume migration in high spatial resolution simulations in which we explicitly resolve the small-scale features. This is done to observe the impacts without incurring numerical errors associated with upscaling, and also as a first step in developing an upscaling approach. We use a geological setting that was the focus of significant appraisal and develop- 


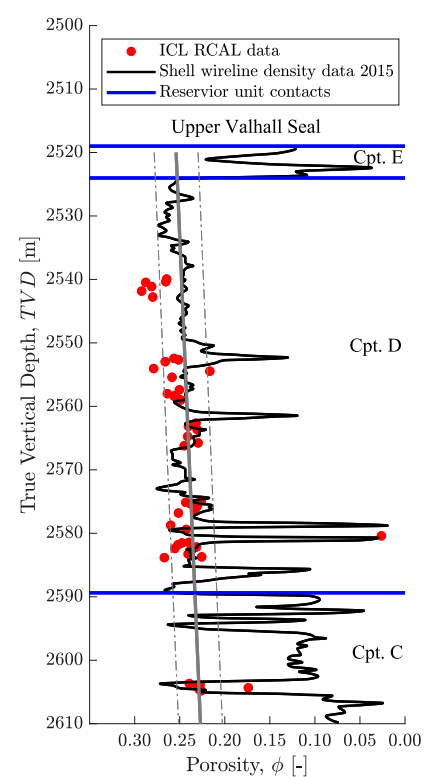

(a)

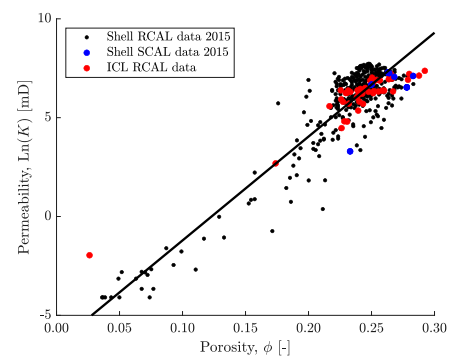

(b)

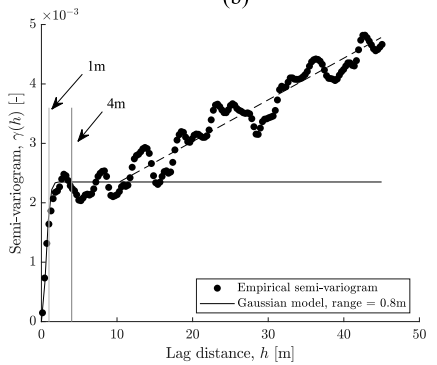

(d)

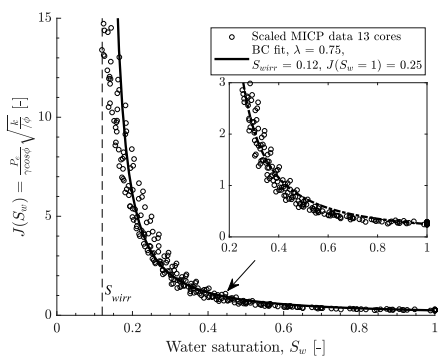

(c)

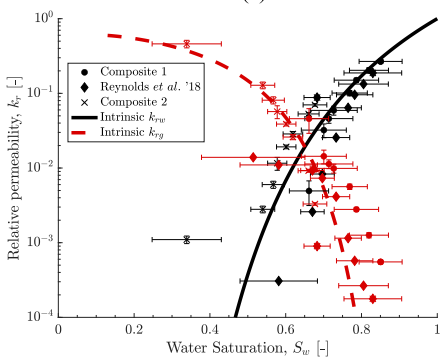

(e)

Figure 2. Multiphase flow characteristics with depth through well 14/29a-3 in the Goldeneye field, North Sea, UK. (a) Neutron density derived wire-line log porosity (Shell data, (Shell U. K. Limited, 2015)) against rock core plug sample data from nitrogen porosimetry (Imperial College London (ICL) regular core analysis laboratory (RCAL) data). The solid grey line represents the porosity depth trend $\phi=-0.0003 T V D+1.01$, with dashed lines showing the standard deviation measured from combined Shell and ICL data. (b) Porosity - permeability relationship, the solid black line represents $\ln (K)=52.544 \phi-6.4656$. (c) Mercury intrusion capillary pressures for 13 plugs comprising the composites, scaled using the measured porosity and permeability (Leverett, 1941). (d) Semi-variogram plot of porosity at increasing lag distance (depth). (e) Experimental relative permeabilities for composite cores through the reservoir. Core depths: Composite core $1-$ 2552.4-2555.4m, Reynolds et al. (2018) - 2562.7-2568.7m, Composite core 2 - 2603.6-2604.9m.

ment activity for an industrial-scale $\mathrm{CO}_{2}$ storage project - the Captain Sandstone Formation in the Goldeneye field, North Sea, UK (Tucker \& Tinios, 2017). The primary injection unit, the Captain D, is a poorly consolidated, medium grained massive sandstone which fines upwards with typical permeabilities in the range $0.7-1.5$ Darcy. It is an archetype unit in the North Sea, and draws parallels with other active $\mathrm{CO}_{2}$ storage sites such as Sleipner and Snøhvit on the Norwegian Continental shelf (Eiken et al., 2011).

We characterise heterogeneity in the reservoir through laboratory analysis of 46 rock samples, sampled from an exploration well (14/29a-3) comprising the entire 65m vertical interval of the targeted injection site (summarised in Figure 2, experimental methods are detailed in the SI). The porosity and permeability are correlated and show a decreasing trend with depth (Figure 2a,b). The capillary pressure - saturation characteristics were scaled using the Leverett- $J$-scaling (Leverett, 1941), collapsing onto the same intrinsic function describing the interval. Similarly, we find little variation in the viscous limit, intrinsic relative permeability function through the formation (Figure 2e). Heterogeneity in the formation appears in the form of dispersed, low-permeability mud-clasts (Shell U. K. Limited, 2015), with small layers and dish-and-pillar structures of vertical correlation length 1-4m, visible in the core, well-log and semi-variogram data, see Figure 2a,d. These small-features do not 
persist between wells and therefore are constrained to a maximum lateral correlation length of $<300 \mathrm{~m}$.

Constrained by the data, and augmented by the well-log data reported in (Shell U. K. Limited, 2015) we generated synthetic realisations of a $50 \mathrm{~m} \times 5 \mathrm{~m}$ rectangular domain, overlain by an impermeable caprock. The domain represents a subvolume of the Captain D formation at depth $2524 \mathrm{~m}$, with average temperature $80^{\circ} \mathrm{C}$ (Shell U. K. Limited, 2015) and average hydrostatic pressure of $25.26 \mathrm{MPa}$; fluid properties, geological and simulation setup are found in the SI. We vary the correlation length of heterogeneities to generate layers of varying lateral length. Vertical correlation lengths, $r_{y}$, are varied between $0.1-5 \mathrm{~m}$, and horizontal correlation lengths, $r_{x}$, from $0.1-50 \mathrm{~m}$, consistent with the petrophysical evidence. Porosity, permeability and capillary pressure heterogeneity are fully correlated through the petrophysical relationships and Leverett-J scaling detailed in Figure 2a, b, c, and further in the SI. The spatially homogeneous, intrinsic relative permeabilities from Figure 2e are prescribed everywhere in the domain. We simulate the isothermal, incompressible lateral migration of $\mathrm{CO}_{2}$ and 1 Molal $\mathrm{NaCl}$ brine. The domain is initially brine saturated at hydrostatic pressure, with $\mathrm{CO}_{2}$ subsequently injected at a constant rate through the left hand boundary.

We observe up to a $200 \%$ increase in plume migration rate as a result of the layered, anisotropic heterogeneities in the capillary pressure characteristic (Heterogeneous $P_{e}$ in Figure $3 \mathrm{~b}$ ). The results are scaled against a base-case representing the mean of the isotropic, uncorrelated cases (Figure 3a, bottom heterogeneous). We see similar qualitative enhancements when the migration speeds are compared directly to the corresponding homogeneous cases (see SI figure S16; migration is enhanced by up to $100 \%$ ).

Figure 3 shows that the $\mathrm{CO}_{2}$ plumes in anisotropic cases are elongated in the domain compared to isotropic cases, and homogeneous $P_{e}$ cases. The plumes migrate laterally much further for the same injected volume. The $\mathrm{CO}_{2}$ has preferentially saturated low entry pressure regions (visible in the entry pressure maps) creating high mobility regions through which the $\mathrm{CO}_{2}$ can rapidly migrate. This applies generally to simulation results under the range of heterogeneity realizations and injection rates shown in Figure 3b,c. They cover a wide range of flow regimes defined by the capillary number, $N_{c}$, created by varying the lateral injection velocity $U_{d}$ from $0.002-20 \mathrm{~m} \cdot$ day $^{-1}$, changing the force balance from capillary to viscous dominated. As the degree of anisotropy in the capillary pressure heterogeneity increases, the migration speed of the plume increases significantly (Figure 3b, isotropic cases are shown in the SI).

The impact is also almost entirely a result of heterogeneity in capillary pressure characteristics alone, and not permeability and porosity. The homogeneous results in Figure $3 \mathrm{a}$ and the black points in Figure $3 \mathrm{~b}$ are results from simulations with domains heterogeneous in porosity and permeability, but homogeneous in capillary pressure characteristics. There is relatively little impact on the plume shape and breakthrough time when varying the correlation length of the permeability and porosity.

The lateral migration speed is generally faster over the entire range of capillary numbers when the dimensionless breakthrough time from the anisotropic cases are compared to the isotropic cases in Figure 3c. However, they are generally much faster at low to moderate capillary numbers, with the impact of heterogeneities becoming less pronounced at high capillary numbers. At larger correlation lengths and length ratios, the variance in breakthrough time increases, indicating the increase in flow path tortuosity and system representativeness. The error bar ranges reported in Figure 3b indicate this variance, showing that the same general trends hold at larger sizes. There are some outliers in the anisotropic data, with slow breakthrough times; these occur in cases where both correlation lengths approach the respective system size, which in some instances can retard the flow. 

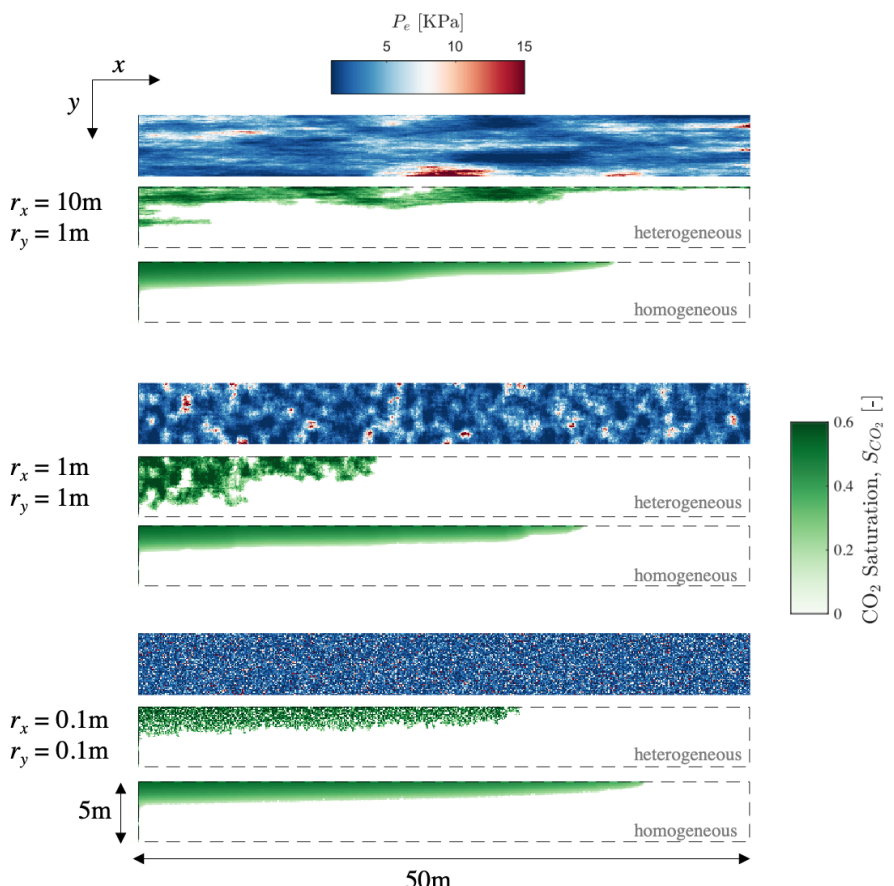

(a)

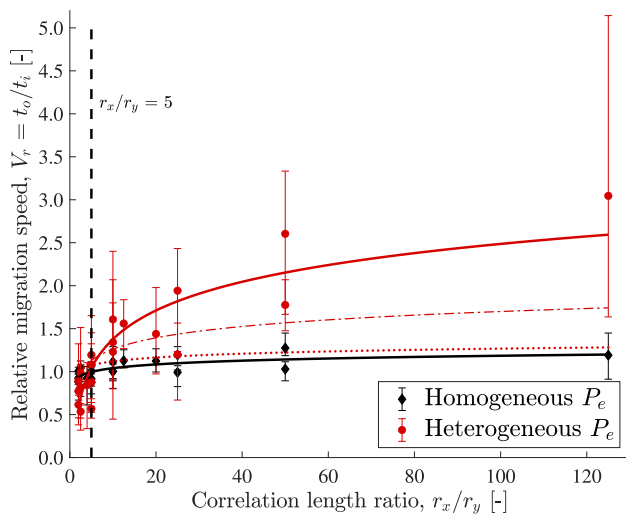

(b)

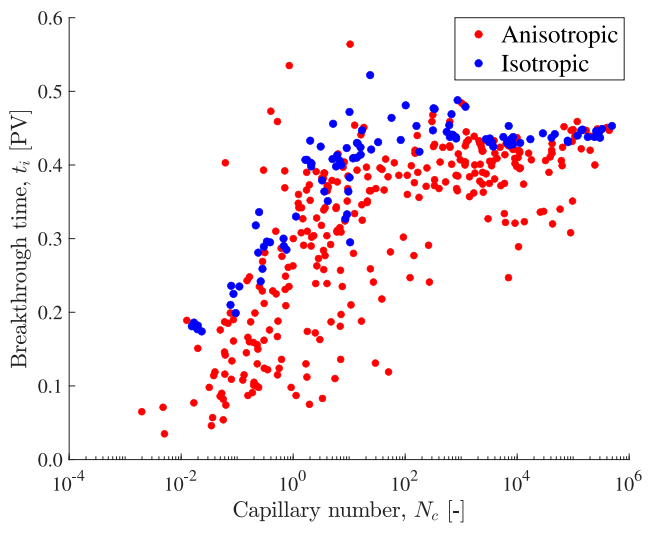

(c)

Figure 3. The impact of small-scale heterogeneities on lateral $\mathrm{CO}_{2}$ migration. (a) Entry pressure fields, and $\mathrm{CO}_{2}$ saturation distributions after 0.1 pore-volumes (PV) of injection for three different geological settings, with $U_{d}=0.002 \mathrm{~m} \cdot$ day $^{-1}$. At $\mathrm{t}=0.1 \mathrm{PV}$, the top heterogeneous case has just broken through. (b) Relative migration speed, $V_{r}$, at low flow potential as a function of correlation length ratio (anisotropic cases). $V_{r}$ is the inverse of the relative breakthrough time - specific realization breakthrough times, $t_{i}$, are scaled against the uncorrelated average for the corresponding heterogeneous or homogeneous $P_{e}$ case, $t_{0}$, in which $r_{x}=r_{y}=0.1 \mathrm{~m}$ (bottom plots in (a)). Each data point represents the mean from 5 different geostatistical realizations, with error bars showing the range. Multiple points at a given $r_{x} / r_{y}$ have different absolute $r_{x}$ and $r_{y}$, but maintain the aspect ratio. The solid, dashed-dotted and dotted lines highlight log curve fits through $U_{d}=0.002,0.2$ and $20 \mathrm{~m} \cdot$ day $^{-1}$ data respectively. Only the $U_{d}=0.002 \mathrm{~m} \cdot$ day $^{-1}$ data points are shown explicitly for clarity. (c) Plume breakthrough times for heterogeneous $P_{e}$ cases as a function of capillary number $N_{c}$. 
As $N_{c}$ increases in Figure 3c, the breakthrough time correspondingly increases, until it reaches a plateau at $N_{c} \approx 10^{2}$. The increase in breakthrough time occurs due to the greater vertical sweep of the plume as the flow rate and $N_{c}$ increase, and the plume behaviour in the plateau regime is usually referred to as viscous dominated. The viscous limit at $N_{c} \approx 10^{2}$ is similar to both previous experimental and modelling studies at a range of scales (Jackson et al., 2018; Virnovsky et al., 2004). The $N_{c}$ reported in Figure 3c also highlights the increase in pressure buildup in the isotropic systems compared to anisotropic systems, for a given flow rate. For a fixed pressure buildup, the isotropic heterogeneity reduces the overall system injectivity. The elevated pressure plume is also a concern in the far-field, as it diffuses and extends beyond the physical $\mathrm{CO}_{2}$ footprint, potentially causing brine leakage into shallow formations among other effects (Cihan et al., 2013).

\section{Field-scale implications \& discussion}

Conventionally, the field-scale impact of capillary pressure has been evaluated without consideration of small-scale heterogeneities. In homogeneous reservoirs capillarity leads to an increase in the sweep of the plume and retardation of its lateral migration (Golding et al., 2013; Becker et al., 2017). We have shown that the presence of structured heterogeneities can lead to an outcome which has qualitatively the opposite impact. Capillary heterogeneity provides a mechanism for rapidly elongating and accelerating the plume migration. We now demonstrate the field-scale implications of the above results by considering a full-field model of the Captain sandstone formation in which rigorous upscaling techniques have been applied to honour the impacts observed at high resolution.

We use a novel upscaling approach (detailed and validated in the SI) to demonstrate the combined impacts of layered capillary heterogeneities in a field-scale setting, during both vertical and lateral migration regimes. The upscaling method allows the incorporation of fine-scale capillary heterogeneity impacts in models with much larger cell sizes, through generation of equivalent, macroscopic flow functions. This permits analysis of large systems that would be insurmountable with fine-scale grids.

We use a $2 \mathrm{~km}$ East-West transect through the centre of well $14 / 29 \mathrm{a}-3$ to generate a $2 \mathrm{D}$ model of the Captain D sandstone in the Goldeneye field. The model has capillary pressure heterogeneities in line with previous petrophysical analysis, with correlations $r_{x}=50 \mathrm{~m}$, $r_{y}=2 \mathrm{~m}$. Carbon dioxide is injected with outlet velocities of $0.01 \mathrm{~m} /$ day into a central well (larger injection rates are shown in the SI), which is perforated through the bottom $1 / 3 \mathrm{rd}$ of the domain, shown in Figure 4a.

Snapshots of the plume location at different times are shown in $4 \mathrm{~b}-\mathrm{d}$, illustrating the key impacts of small-scale capillary heterogeneities in field-scale $\mathrm{CO}_{2}$ flow. The top plots show the case with capillary heterogeneity, the bottom plots show the homogeneous case (still with permeability and porosity heterogeneity to isolate the impact of capillary heterogeneity). Alongside this, the distance from the top of the plume to the caprock $\left(R_{1}\right)$ and the lateral migration distance of the plume along the caprock $\left(R_{2}\right)$ are shown through time in Figure 4e.

The initial buoyant rise of $\mathrm{CO}_{2}$ is significantly retarded by the anisotropic capillary heterogeneities, which act as vertical flow baffles. The flow is spread underneath these baffles, pooling until the column height underneath is great enough to overcome the high capillary entry pressure of the local heterogeneity. The migration time to reach the cap rock is 0.035 pore volumes for the heterogeneous case, but only 0.005 pore volumes for the homogeneous case, a 7 fold decrease.

The impact of heterogeneities on lateral migration is observed after the initial buoyant rise. The $\mathrm{CO}_{2}$ sweeps laterally underneath the cap rock, still largely driven by the buoyancy of the vertical $\mathrm{CO}_{2}$ column underneath, shown in $4 \mathrm{c}-\mathrm{d}$. In the heterogeneous case, the plume extends more thinly underneath the caprock, migrating in regions of low entry pressure. 


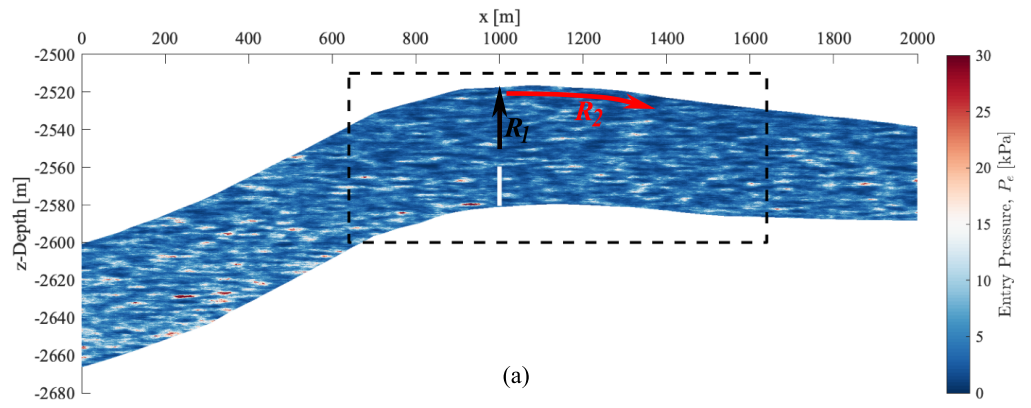

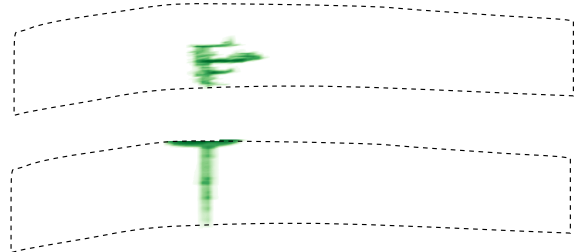

(b)

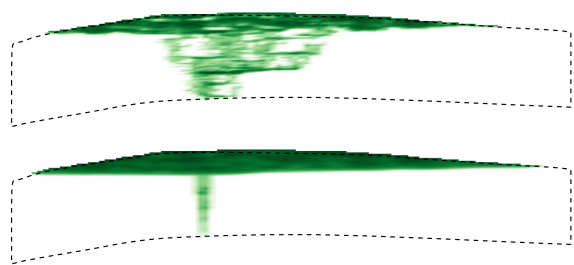

(d)

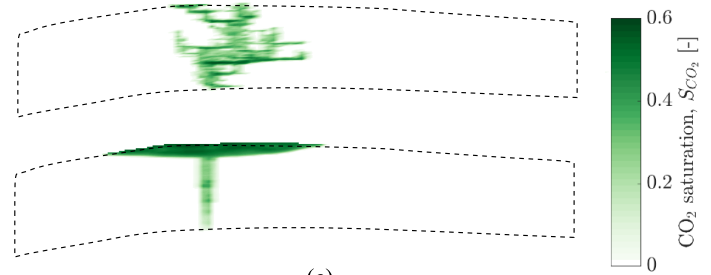

(c)

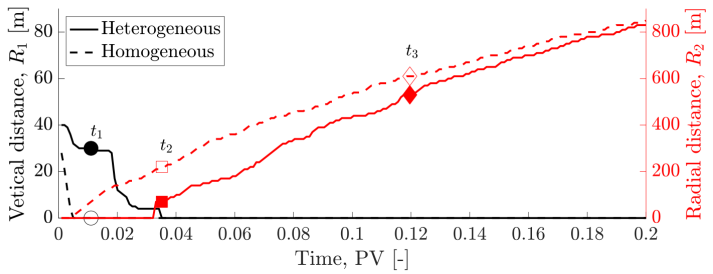

(e)

Figure 4. Field-scale implications of small-scale capillary heterogeneity in the Goldeneye field, North Sea, UK, $U_{d}=0.01 \mathrm{~m} /$ day, $N_{c} \approx 0.02$. (a) Capillary entry pressure field realization of a $2 \mathrm{D}$ east-west section through well 14-29a3 in the Goldeneye field, with $r_{x}=50 \mathrm{~m}, r_{y}=2 \mathrm{~m}$. The white line highlights the injection interval. (b-d) Zoomed in snapshots of the $\mathrm{CO}_{2}$ plume at $t_{1}=$ $0.012 \mathrm{PV}, 1$ year; $t_{2}=0.036 \mathrm{PV}, 3$ years; and $t_{3}=0.12 \mathrm{PV}, 10$ years respectively. The dashed box in (a) shows the zoomed in region. In each subfigure, the top plots are the fully heterogeneous result, whilst the bottom plots have homogeneous capillary pressure and relative permeability. (e) Plume travel time comparison for the two cases in (b) - (d). $R_{1}$ is the central vertical distance from the top of the plume to the caprock (initially $\approx 40 \mathrm{~m}$ from the top of the injection well to the caprock), and $R_{2}$ is the growing lateral extent of the plume directly under the caprock for $\mathrm{x}>1000 \mathrm{~m}$, once the plume has reached the caprock. The $R_{1}$ and $R_{2}$ direction vectors are highlighted in (a). Times $t_{1}, t_{2}$ and $t_{3}$ in (e) correspond to those in (b-d), respectively.

Indeed, given the initial retardation of the vertical migration, the plume migrates much quicker laterally in the heterogeneous case compared to the homogeneous case, as can be seen in Figure 4e. It migrates in high speed 'bursts' when the flow path aligns with the anisotropic heterogeneities, ultimately catching the homogeneous plume. The results here show the combined impact of layered capillary heterogeneities in the field when flow migration is aligned predominantly transverse and parallel to layers, respectively. The inhibiting impact of layering on upward migration and trapping has been studied previously (B. Li \& Benson, 2015). This effect is dependent on the extent to which the layers cannot be bypassed by the fluid. Layers with shorter correlation lengths in one lateral dimension will provide a bypass route for the flow, partly offsetting the inhibition effect. 
The case here-in represents a relatively conservative scenario for the enhancement of lateral migration speed due to the topography of the Goldeneye field. The steep anticline causes $\mathrm{CO}_{2}$ to pool and migrate both laterally and downward against the heterogeneities, mitigating the enhanced rate of plume migration. In cases of a flat topography (i.e. in the examples in Section 3), an up-dip migration, or a shallow anticline (i.e. at Sleipner (Furre et al., 2017)), the enhancement would be significantly more prominent. Although the final lateral extent appears similar in Figure 4, the lateral spreading is much faster in the heterogeneous case (Figure 4e).

Small-scale, capillary heterogeneities could have contributed significantly to the rapid plume migration, elongation and early monitoring well breakthrough that has been observed in several field sites, i.e. Sleipner, North Sea, Norway (Chadwick et al., 2009; G. Williams \& Chadwick, 2012); In Salah, Algeria (Ringrose et al., 2013); Frio stage I and II projects, Texas, USA (Hovorka et al., 2006; Daley et al., 2011); Cranfield, Mississippi, USA (Hosseini et al., 2013) and the Otway stage 2 project, Otway, Victoria, Australia (Dance et al., 2019). Small-scale capillary features (i.e. 1-10s of metres) are generally not included in the field-scale simulation of these sites, largely due to model and/or geological resolution. The leading order impacts of small heterogeneities suggests that these problems should be revisited making use of characterisation, upscaling, and modelling techniques that honor the impacts these heterogeneities have on field-scale flow.

The characterisation and upscaling methodology herein provides a method for tractably simulating large scale flows at low capillary number, including the impacts of small-scale heterogeneities. This is particularly important in uncertainty analysis, allowing different geological realizations to be run quickly to see potential impacts of different interpretations, and when new information comes through from field operations (Dance et al., 2019). The ability of numerical models to conform to observed plume migration is vital for demonstrating compliance with regulators, i.e. within a specified area of review (Court et al., 2012; Pawar et al., 2017), and key in the scale up of $\mathrm{CO}_{2}$ injection from an individual site (i.e. megatonnes), to the gigatonne scales required for large scale climate change mitigation.

\section{Acknowledgements}

We gratefully acknowledge funding from the Natural Environment Research Council (Grant number: NE/N016173/1). We acknowledge Computer Modelling Group (CMG) for providing access to IMEX and Schlumberger for providing access to ECLIPSE. We thank Katie Bell, Olivia Sloane, Ben Niu, Ed Bailey, Saurabh Shah, and Vincenzo Cunsolo from Imperial College London for laboratory assistance in the petrophysical characterisation. We thank Ronny Pini and Jerome Neufeld for many helpful discussion on capillary pressure heterogeneity and Silvia De Simone for discussions on realistic boundary conditions in subsurface flow.

Data associated with this work is hosted on the BGS National Geoscience Data Centre at www.bgs.ac.uk/ukccs/accessions/index.html\#item133945. The authors declare no conflicts of interests.

\section{References}

Akin, S., \& Kovscek, A. R. (2003). Computed tomography in petroleum engineering research. Geological Society, London, Special Publications, 215(1), 23-38. doi: 10.1144/gsl.sp.2003.215.01.03

Bachu, S., Bonijoly, D., Bradshaw, J., Burruss, R., Holloway, S., Christensen, N. P., \& Mathiassen, O. M. (2007). $\mathrm{CO}_{2}$ storage capacity estimation: Methodology and gaps. International Journal of Greenhouse Gas Control, 1(4), 430-443. doi: 10.1016/s1750 $-5836(07) 00086-2$

Bear, J. (1989). Dynamics of fluids in porous media. Dover Publications Inc. 
Becker, B., Guo, B., Bandilla, K., Celia, M. A., Flemisch, B., \& Helmig, R. (2017). A pseudo-vertical equilibrium model for slow gravity drainage dynamics. Water Resources Research, 53(12), 10491-10507. doi: 10.1002/2017wr021644

Birkholzer, J. T., Oldenburg, C. M., \& Zhou, Q. (2015). CO $\mathrm{CO}_{2}$ migration and pressure evolution in deep saline aquifers. International Journal of Greenhouse Gas Control, 40, 203-220. doi: 10.1016/j.ijggc.2015.03.022

Blunt, M., King, M. J., \& Scher, H. (1992). Simulation and theory of two-phase flow in porous media. Physical Review A, 46(12), 7680-7699. doi: 10.1103/physreva.46.7680

Braun, C., Helmig, R., \& Manthey, S. (2005). Macro-scale effective constitutive relationships for two-phase flow processes in heterogeneous porous media with emphasis on the relative permeability-saturation relationship. Journal of Contaminant Hydrology, 76(1-2), 47-85. doi: 10.1016/j.jconhyd.2004.07.009

Cavanagh, A. J., \& Haszeldine, R. S. (2014). The Sleipner storage site: Capillary flow modeling of a layered $\mathrm{CO}_{2}$ plume requires fractured shale barriers within the Utsira Formation. International Journal of Greenhouse Gas Control, 21, 101-112. doi: 10.1016/j.ijggc.2013.11.017

Celia, M. A., Bachu, S., Nordbotten, J. M., \& Bandilla, K. W. (2015). Status of $\mathrm{CO}_{2}$ storage in deep saline aquifers with emphasis on modeling approaches and practical simulations. Water Resources Research, 51 (9), 6846-6892. doi: 10.1002/2015wr017609

Chadwick, R., Noy, D., Arts, R., \& Eiken, O. (2009). Latest time-lapse seismic data from Sleipner yield new insights into $\mathrm{CO}_{2}$ plume development. Energy Procedia, 1(1), 2103-2110. doi: 10.1016/j.egypro.2009.01.274

Chierici, G. (1984). Novel relations for drainage and imbibition relative permeabilities. SPE Journal, 275-276. doi: 10.2118/10165-pa

Chilès, J.-P., \& Delfiner, P. (2012). Geostatistics: Modeling spatial uncertainty. Wiley.

Cihan, A., Birkholzer, J. T., \& Zhou, Q. (2013). Pressure buildup and brine migration during co2 storage in multilayered aquifers. Groundwater, 51(2), 252-267. doi: 10.1111/ j.1745-6584.2012.00972.x

Corbett, P. W. M., Ringrose, P. S., Jensen, J. L., \& Sorbie, K. S. (1992). Laminated clastic reservoirs: The interplay of capillary pressure and sedimentary architecture. In SPE 24699 Presented at the 67th Annual Technical Conference and Exhibition of the Society of Petroleum Engineers, Washington D.C., October 4-7, 1992. doi: 10.2118/24699-ms

Court, B., Bandilla, K. W., Celia, M. A., Buscheck, T. A., Nordbotten, J. M., Dobossy, M., \& Janzen, A. (2012). Initial evaluation of advantageous synergies associated with simultaneous brine production and $\mathrm{CO}_{2}$ geological sequestration. International Journal of Greenhouse Gas Control, 8, 90-100. doi: 10.1016/j.ijggc.2011.12.009

Cowton, L. R., Neufeld, J. A., White, N. J., Bickle, M. J., White, J. C., \& Chadwick, R. A. (2016). An inverse method for estimating thickness and volume with time of a thin $\mathrm{CO}_{2}$-filled layer at the Sleipner Field, North Sea. Journal of Geophysical Research: Solid Earth, 121(7), 5068-5085. doi: 10.1002/2016jb012895

Cowton, L. R., Neufeld, J. A., White, N. J., Bickle, M. J., Williams, G. A., White, J. C., \& Chadwick, R. A. (2018). Benchmarking of vertically-integrated $\mathrm{CO}_{2}$ flow simulations at the Sleipner Field, North Sea. Earth and Planetary Science Letters, 491, 121-133. doi: $10.1016 /$ j.epsl.2018.03.038

Daley, T. M., Ajo-Franklin, J. B., \& Doughty, C. (2011). Constraining the reservoir model of an injected $\mathrm{CO}_{2}$ plume with crosswell CASSM at the Frio-II brine pilot. International Journal of Greenhouse Gas Control, 5(4), 1022-1030. doi: 10.1016/j.ijggc.2011.03 .002

Dance, T., LaForce, T., Glubokovskikh, S., Ennis-King, J., \& Pevzner, R. (2019). Illuminating the geology: Post-injection reservoir characterisation of the CO2CRC Otway site. International Journal of Greenhouse Gas Control, 86, 146-157. doi: 10.1016/j.ijggc.2019.05.004

Dance, T., \& Paterson, L. (2016). Observations of carbon dioxide saturation distribution and residual trapping using core analysis and repeat pulsed-neutron logging at the CO2CRC Otway site. International Journal of Greenhouse Gas Control, 47, 210-220. 
doi: $10.1016 /$ j.ijggc.2016.01.042

Debbabi, Y., Jackson, M., Hampson, G., \& Salinas, P. (2017). Capillary heterogeneity trapping and crossflow in layered porous media. Transport in Porous Media. doi: $10.1007 / \mathrm{s} 11242-017-0915-\mathrm{z}$

Department for Business, Energy \& Industrial Strategy. (2015). 2015 UK Greenhouse gas emission, Final figures. Statistical Release: National Statistics. UK Government Report.

Durlofsky, L. (1991). Numerical calculation of equivalent grid block permeability tensors for heterogeneous porous media. Water Resources Research, 27(5), 699-708. doi: 10.1029/91wr00107

Efendiev, Y., \& Galvis, J. (2011). Coarse-grid multiscale model reduction techniques for flows in heterogeneous media and applications. In Lecture notes in computational science and engineering (pp. 97-125). Springer Berlin Heidelberg. doi: 10.1007/ 978-3-642-22061-6_4

Eiken, O., Ringrose, P., Hermanrud, C., Nazarian, B., Torp, T. A., \& Høier, L. (2011). Lessons learned from 14 years of CCS operations: Sleipner, In Salah and Snøhvit. Energy Procedia, 4, 5541-5548. doi: 10.1016/j.egypro.2011.02.541

Ekrann, S., \& Aasen, J. O. (2000). Steady-state upscaling. Transport in Porous Media, $41(3), 245-262$. doi: 10.1023/a:1006765424927

Ferrand, L. A., \& Celia, M. A. (1992). The effect of heterogeneity on the drainage capillary pressure-saturation relation. Water Resources Research, 28(3), 859-870. doi: 10.1029/ 91WR02679

Furre, A.-K., Eiken, O., Alnes, H., Vevatne, J. N., \& Kiær, A. F. (2017, jul). 20 years of monitoring CO2-injection at sleipner. Energy Procedia, 114, 3916-3926. doi: 10.1016/ j.egypro.2017.03.1523

Gasda, S. E., Nilsen, H. M., Dahle, H. K., \& Gray, W. G. (2013). Effective models for $\mathrm{CO}_{2}$ migration in geological systems with varying topography. Water Resources Research, 48(10). doi: 10.1029/2012WR012264

Gelhar, L. (1993). Stochastic subsurface hydrology. Prentice-Hall.

Gershenzon, N. I., Ritzi Jr., R. W., Dominic, D. F., Soltanian, M., Mehnert, E., \& Okwen, R. T. (2015). Influence of small-scale fluvial architecture on $\mathrm{CO}_{2}$ trapping processes in deep brine reservoirs. Water Resources Research, 51 (10), 8240-8256. doi: 10.1002/ 2015WR017638

Gershenzon, N. I., Soltanian, M., Ritzi Jr, R. W., \& Dominic, D. F. (2014). Influence of small scale heterogeneity on $\mathrm{CO}_{2}$ trapping processes in deep saline aquifers. Energy Procedia, 59, 166-173. doi: 10.1016/j.egypro.2014.10.363

Gilmore, K. A., Neufeld, J. A., \& Bickle, M. J. (2020). $\mathrm{CO}_{2}$ dissolution trapping rates in heterogeneous porous media. Geophysical Research Letters, 47(12), e2020GL087001. doi: 10.1029/2020GL087001

Golding, M. J., Huppert, H. E., \& Neufeld, J. A. (2013). The effects of capillary forces on the axisymmetric propagation of two-phase, constant-flux gravity currents in porous media. Physics of Fluids, 25(3), 036602. doi: 10.1063/1.4793748

Gringarten, E., \& Deutsch, C. V. (2001). Teacher's aide variogram interpretation and modeling. Mathematical Geology, 33(4), 507-534.

Guo, B., Zheng, Z., Bandilla, K. W., Celia, M. A., \& Stone, H. A. (2016). Flow regime analysis for geologic $\mathrm{CO}_{2}$ sequestration and other subsurface fluid injections. International Journal of Greenhouse Gas Control, 53, 284-291. doi: 10.1016/j.ijggc.2016.08.007

Halladay, A., Bacci, V. O., O’Brien, S., \& Hindriks, K. (2018). Results From The Second Monitor DAS VSP At Quest CCS. In EAGE Fifth $\mathrm{CO}_{2}$ Geological Storage Workshop, Utrecht, Netherlands, November. doi: https://doi.org/10.3997/2214-4609.2018029

Hassanzadeh, H., Pooladi-Darvish, M., \& Keith, D. W. (2007). Scaling behavior of convective mixing, with application to geological storage of $\mathrm{CO}_{2}$. AIChE Journal, 53(5), 1121-1131. doi: 10.1002/aic.11157

Hesse, M., Tchelepi, H. A., \& Orr, F. M. (2006). Scaling analysis of the migration of $\mathrm{CO}_{2}$ in saline aquifers. In SPE annual technical conference and exhibition. Society of 
Petroleum Engineers. doi: 10.2118/102796-ms

Hilden, S. T., \& Berg, C. F. (2016). An analysis of unsteady flooding processes: Varying force balance and the applicability of steady-state upscaling. Transport in Porous Media, 115(1), 125-152. doi: 10.1007/s11242-016-0757-0

Hodneland, E., Gasda, S., Kaufmann, R., Bekkvik, T. C., Hermanrud, C., \& Midttømme, K. (2019). Effect of temperature and concentration of impurities in the fluid stream on co2 migration in the utsira formation. International Journal of Greenhouse Gas Control, 83, 20 - 28. doi: https://doi.org/10.1016/j.ijggc.2019.01.020

Hosseini, S. A., Lashgari, H., Choi, J. W., Nicot, J.-P., Lu, J., \& Hovorka, S. D. (2013). Static and dynamic reservoir modeling for geological $\mathrm{CO}_{2}$ sequestration at Cranfield, Mississippi, U.S.A. International Journal of Greenhouse Gas Control, 18, 449-462. doi: 10.1016/j.ijggc.2012.11.009

Hovorka, S. D., Benson, S. M., Doughty, C., Freifeld, B. M., Sakurai, S., Daley, T. M., ... Knauss, K. G. (2006). Measuring permanence of $\mathrm{CO}_{2}$ storage in saline formations: the Frio experiment. Environmental Geosciences, 13(2), 105-121. doi: 10.1306/ eg. 11210505011

Hulea, I. N., \& Nicholls, C. A. (2012). Carbonate rock characterization and modeling: Capillary pressure and permeability in multimodal rocks - a look beyond sample specific heterogeneity. AAPG Bulletin, 96(9), 1627-1642. doi: 10.1306/02071211124

IPCC. (2005). Special Report on Carbon Dioxide Capture and Storage, prepared by Working Group III of the Intergovernmental Panel on Climate Change. IPCC, Geneva, Switzerland, 442.

Jackson, S., Lin, Q., \& Krevor, S. (2020). Representative elementary volumes, hysteresis and heterogeneity in multiphase flow from the pore to continuum scale. Water Resources Research. (2019WR026396) doi: 10.1029/2019WR026396

Jackson, S. J., Agada, S., Reynolds, C. A., \& Krevor, S. (2018). Characterizing drainage multiphase flow in heterogeneous sandstones. Water Resources Research, 54 (4), 31393161. doi: $10.1029 / 2017$ wr022282

Jackson, S. J., \& Krevor, S. (2019). Characterization of hysteretic multiphase flow from the $\mathrm{mm}$ to $\mathrm{m}$ scale in heterogeneous rocks. E3S Web of Conferences, 89, 02001. doi: $10.1051 / \mathrm{e} 3 \mathrm{sconf} / 20198902001$

Jin, M., Mackay, E. J., Quinn, M., Hitchen, K., \& Akhurst, M. (2012). Evaluation of the $\mathrm{CO}_{2}$ storage capacity of the captain sandstone formation. In SPE europec/EAGE annual conference. Society of Petroleum Engineers. doi: 10.2118/154539-ms

Jonoud, S., \& Jackson, M. (2008). New criteria for the validity of steady-state upscaling. Transport in Porous Media, 71, 53-73.

Juanes, R., Spiteri, E. J., Orr, F. M., \& Blunt, M. J. (2006). Impact of relative permeability hysteresis on geological $\mathrm{CO}_{2}$ storage. Water Resources Research, 42(12). doi: 10.1029/ 2005 wr004806

Jung, J.-W., \& Wan, J. (2012). Supercritical $\mathrm{CO}_{2}$ and ionic strength effects on wettability of silica surfaces: Equilibrium contact angle measurements. Energy \& Fuels, 26 (9), 6053-6059. doi: 10.1021/ef300913t

Jung, Y., Pau, G. S. H., Finsterle, S., \& Pollyea, R. M. (2017). TOUGH3: A new efficient version of the TOUGH suite of multiphase flow and transport simulators. Computers E Geosciences, 108, 2-7. doi: 10.1016/j.cageo.2016.09.009

Kestin, J., Khalifa, H. E., \& Correia, R. J. (1981). Tables of the dynamic and kinematic viscosity of aqueous $\mathrm{NaCl}$ solutions in the temperature range $20-150^{\circ} \mathrm{C}$ and the pressure range 0.1-35 MPa. Journal of Physical and Chemical Reference Data, 10(1), 71-88. doi: $10.1063 / 1.555641$

Krause, M. (2012). Modeling and investigation of capillary heterogeneity on multiphase flow of $\mathrm{CO}_{2}$ and brine [Ph.D. thesis]. Ph.D. thesis, Stanford University.

Krause, M., \& Benson, S. (2015). Accurate determination of characteristic relative permeability curves. Advances in Water Resources, 83, 376-388. doi: 10.1016/ j.advwatres.2015.07.009

Krause, M., Krevor, S., \& Benson, S. (2013). A procedure for the accurate determination 
of sub-core scale permeability distributions with error quantification. Transport in Porous Media, 93(3), 565-588. doi: 10.1007/s11242-013-0161-y

Krevor, S., Blunt, M. J., Benson, S. M., Pentland, C. H., Reynolds, C., Al-Menhali, A., \& Niu, B. (2015). Capillary trapping for geologic carbon dioxide storage - from pore scale physics to field scale implications. International Journal of Greenhouse Gas Control, 40, 221-237. doi: 10.1016/j.ijggc.2015.04.006

Krevor, S. C. M., Pini, R., Li, B., \& Benson, S. M. (2011). Capillary heterogeneity trapping of $\mathrm{CO}_{2}$ in a sandstone rock at reservoir conditions. Geophysical Research Letters, 38 , L15401. doi: 10.1029/2011gl048239

Kyte, J., \& Berry, D. (1975). New pseudo functions to control numerical dispersion. Society of Petroleum Engineers Journal, 15(04), 269-276. doi: 10.2118/5105-pa

Lemmon, E., McLinden, M. O., \& Friend, D. G. (Accessed 2019). Thermophysical properties of fluid systems. NIST Chemistry WebBook, NIST Standard Reference Database Number 69

Leverett, M. C. (1941). Capillary behavior in porous solids. Transactions of the AIME, 142(01), 152-169. doi: 10.2118/941152-g

Li, B., \& Benson, S. (2015). Influence of small-scale heterogeneity on upward $\mathrm{CO}_{2}$ plume migration in storage aquifers. Advances in Water Resources, 83, 389-404. doi: 10 $.1016 /$ j.advwatres.2015.07.010

Li, B., Tchelepi, H. A., \& Benson, S. M. (2013). Influence of capillary-pressure models on $\mathrm{CO}_{2}$ solubility trapping. Advances in Water Resources, 62, 488-498. doi: 10.1016/ j.advwatres.2013.08.005

Li, X., Boek, E., Maitland, G. C., \& Trusler, J. P. M. (2012). Interfacial Tension of $\left(\right.$ Brines $\left.+\mathrm{CO}_{2}\right):(0.864 \mathrm{NaCl}+0.136 \mathrm{KCl})$ at Temperatures between $(298$ and 448$)$ $\mathrm{K}$, Pressures between (2 and 50) $\mathrm{MPa}$, and Total Molalities of (1 to 5) $\mathrm{mol} \cdot \mathrm{kg}^{-1}$. Journal of Chemical \& Engineering Data, 57(4), 1078-1088. doi: 10.1021/je201062r

Liyanage, R., Cen, J., Krevor, S., Crawshaw, J. P., \& Pini, R. (2018). Multidimensional observations of dissolution-driven convection in simple porous media using x-ray CT scanning. Transport in Porous Media, 126(2), 355-378. doi: 10.1007/s11242-018-1158 $-3$

MacMinn, C., Szulczewski, M., \& Juanes, R. (2011, 12). $\mathrm{CO}_{2}$ migration in saline aquifers. Part 2. Capillary and solubility trapping. Journal of Fluid Mechanics, 688, 321 - 351. doi: $10.1017 /$ jfm.2011.379

Meckel, T., Bryant, S., \& Ganesh, P. R. (2015). Characterization and prediction of $\mathrm{CO}_{2}$ saturation resulting from modeling buoyant fluid migration in $2 \mathrm{D}$ heterogeneous geologic fabrics. International Journal of Greenhouse Gas Control, 34, 85-96. doi: 10.1016/j.ijggc.2014.12.010

Muskat, M., \& Meres, M. W. (1936). The flow of heterogeneous fluids through porous media. Physics, 7(9), 346-363. doi: 10.1063/1.1745403

Neufeld, J. A., Hesse, M. A., Riaz, A., Hallworth, M. A., Tchelepi, H. A., \& Huppert, H. E. (2010). Convective dissolution of carbon dioxide in saline aquifers. Geophysical Research Letters, 37(22). doi: 10.1029/2010gl044728

Niessner, J., Berg, S., \& Hassanizadeh, S. M. (2011). Comparison of Two-Phase Darcy's law with a thermodynamically consistent approach. Transport in Porous Media, 88(1), 133-148. doi: 10.1007/s11242-011-9730-0

Nilsen, H. M., Krogstad, S., Andersen, O., Allen, R., \& Lie, K.-A. (2017). Using sensitivities and vertical-equilibrium models for parameter estimation of $\mathrm{CO}_{2}$ injection models with application to Sleipner Data. Energy Procedia, 114, 3476 - 3495. doi: https://doi.org/ 10.1016/j.egypro.2017.03.1478

Odsæter, L., Berg, C., \& Rustad, A. (2015). Rate dependency in steady-state upscaling. Transport in Porous Media, 110, 565-589. doi: 10.1007/s11242-015-0573-y

Park, S. S., Kim, T. H., Jeong, M. S., \& Lee, K. S. (2016). Evaluating the impacts of fine-scale capillary heterogeneity and wettability on the behavior of buoyancy-driven CO2 migration and trapping mechanisms. Environmental Earth Sciences, 75 (7), 550. doi: $10.1007 / \mathrm{s} 12665-016-5244-\mathrm{y}$ 
Pawar, R., Dempsey, D., \& Guthrie, G. (2017). Effect of permeability heterogeneity on area of review. Energy Procedia, 114, 7459-7465. doi: 10.1016/j.egypro.2017.03.1875

Picchi, D., \& Battiato, I. (2019). Relative permeability scaling from pore-scale flow regimes. Water Resources Research, 55(4), 3215-3233. doi: 10.1029/2018wr024251

Pickup, G. E., \& Stephen, K. D. (2000). An assessment of steady-state scale-up for smallscale geological models. Petroleum Geoscience, 6, 203-210. doi: 10.1144/petgeo.6.3 .203

Pini, R., \& Benson, S. (2013). Simultaneous determination of capillary pressure and relative permeability curves from core-flooding experiments with various fluid pairs. Water Resources Research, 49, 3516-3530. doi: 10.1002/wrcr.20274

Pini, R., Krevor, S., \& Benson, S. (2012). Capillary pressure and heterogeneity for the $\mathrm{CO}_{2}$ /water system in sandstone rocks at reservoir conditions. Advances in Water Resources, 38, 48-59. doi: 10.1016/j.advwatres.2011.12.007

Pittman, E. (1992). Relationship of porosity and permeability to various parameters derived from mercury injection-capillary pressure curves for sandstone. AAPG Bulletin, 76 . doi: 10.1306/bdff87a4-1718-11d7-8645000102c1865d

Pruess, K., \& Spycher, N. (2007). ECO2n - a fluid property module for the TOUGH2 code for studies of $\mathrm{CO}_{2}$ storage in saline aquifers. Energy Conversion and Management, 48(6), 1761-1767. doi: 10.1016/j.enconman.2007.01.016

Quintard, M., \& Whitaker, S. (1988). Two-phase flow in heterogeneous porous media: The method of large-scale averaging. Transport in Porous Media, 3(4), 357-413. doi: $10.1007 / \mathrm{bf} 00233177$

Rabinovich, A., Itthisawatpan, K., \& Durlofsky, L. (2015). Upscaling of $\mathrm{CO}_{2}$ injection into brine with capillary heterogeneity effects. Journal of Petroleum Science and Engineering, 134, 60-75. doi: 10.1016/j.petrol.2015.07.021

Rabinovich, A., Li, B., \& Durlofsky, L. (2016). Analytical approximations for effective relative permeability in the capillary limit. Water Resources Research, 52(4), 76457667. doi: $10.1002 / 2016$ wr019234

Reynolds, C. A., Blunt, M. J., \& Krevor, S. (2018). Multiphase flow characteristics of heterogeneous rocks from $\mathrm{CO}_{2}$ storage reservoirs in the united kingdom. Water Resources Research, 54 (2), 729-745. doi: 10.1002/2017wr021651

Reynolds, C. A., \& Krevor, S. C. (2015). Characterizing flow behaviour for gas injection: Relative permeability of $\mathrm{CO}_{2}$-brine and $\mathrm{N}_{2}$-water in heterogeneous rocks. Water Resources Research, 51(12), 9464-9489. doi: 10.1002/2015wr018046

Ringrose, P., Atbi, M., Mason, D., Espinassous, M., Myhrer, Ø., Iding, M., \& Wright, I. (2009). Plume development around well KB-502 at the In Salah $\mathrm{CO}_{2}$ storage site. First break, 27(1), 1-5.

Ringrose, P., \& Corbett, P. (1994). Controls on two-phase fluid flow in heterogeneous sandstones. Geological Society, London, Special Publications, 78, 141-150. doi: 10 $.1144 /$ gsl.sp.1994.078.01.12

Ringrose, P., Mathieson, A., Wright, I., Selama, F., Hansen, O., Bissell, R., ... Midgley, J. (2013). The In Salah $\mathrm{CO}_{2}$ storage project: Lessons learned and knowledge transfer. Energy Procedia, 37, 6226-6236. doi: 10.1016/j.egypro.2013.06.551

Ringrose, P., Sorbie, K., Corbett, P., \& Jensen, J. (1993). Immiscible flow behaviour in laminated and cross-bedded sandstones. Journal of Petroleum Science and Engineering, 9, 103-124. doi: 10.1016/0920-4105(93)90071-1

Rogers, P. S. Z., \& Pitzer, K. S. (1982). Volumetric properties of aqueous sodium chloride solutions. Journal of Physical and Chemical Reference Data, 11(1), 15-81. doi: 10 $.1063 / 1.555660$

Saadatpoor, E., Bryant, S. L., \& Sepehrnoori, K. (2010). New trapping mechanism in carbon sequestration. Transport in Porous Media, 82, 3-17.

Salinas, P., Pavlidis, D., Xie, Z., Osman, H., Pain, C., \& Jackson, M. (2018). A discontinuous control volume finite element method for multi-phase flow in heterogeneous porous media. Journal of Computational Physics, 352, 602-614. doi: 10.1016/j.jcp.2017.09 .058 
Schmid, K. S., \& Geiger, S. (2012). Universal scaling of spontaneous imbibition for water-wet systems. Water Resources Research, 48(3). doi: 10.1029/2011WR011566

Shell U. K. Limited. (2015). Peterhead CCS Project, Technical - Subsurface and Well Engineering documents (Technical Report). UK Government, Department for Energy and Climate Change.

Shook, M., Li, D., \& Lake, L. (1992). Scaling immiscible flow through permeable media by inspectional analysis. In Situ, 16(4), 311-349. doi: 10.1016/0148-9062(93)91860-1

Trevisan, L., Krishnamurthy, P., \& Meckel, T. (2017). Impact of 3D capillary heterogeneity and bedform architecture at the sub-meter scale on $\mathrm{CO}_{2}$ saturation for buoyant flow in clastic aquifers. International Journal of Greenhouse Gas Control, 56, 237-249. doi: $10.1016 /$ j.ijggc.2016.12.001

Trevisan, L., Pini, R., nd J.T. Birkholzer, A. C., Zhou, Q., González-Nicolás, A., \& Illangasekare, T. (2017). Imaging and quantification of spreading and trapping of carbon dioxide in saline aquifers using meter-scale laboratory experiments. Water Resources Research, 53(1), 485-502. doi: 10.1002/2016wr019749

Tucker, O., \& Tinios, L. (2017). Experience in Developing the Goldeneye Storage Permit Application. Energy Procedia, 114, 7466-7479. doi: 10.1016/j.egypro.2017.03.1880

Ursino, N., \& Gimmi, T. (2004). Combined effect of heterogeneity, anisotropy and saturation on steady state flow and transport: Structure recognition and numerical simulation. Water Resources Research, 40(1). doi: 10.1029/2003wr002180

Virnovsky, G., Friis, H., \& Lohne, A. (2004). A steady-state upscaling approach for immiscible two-phase flow. Transport in Porous Media, 54, 167-192.

Williams, G., \& Chadwick, A. (2012). Quantitative seismic analysis of a thin layer of $\mathrm{CO}_{2}$ in the Sleipner injection plume. Geophysics, $77(6), \mathrm{R} 245-\mathrm{R} 256$. doi: 10.1190/ geo2011-0449.1

Williams, G., Chadwick, R., \& Vosper, H. (2018). Some thoughts on Darcy-type flow simulation for modelling underground $\mathrm{CO}_{2}$ storage, based on the Sleipner $\mathrm{CO}_{2}$ storage operation. International Journal of Greenhouse Gas Control, 68, 164-175. doi: 10 .1016 j.ijggc.2017.11.010

Williams, G. A., \& Chadwick, R. A. (2017). An improved history-match for layer spreading within the sleipner plume including thermal propagation effects. Energy Procedia, 114, 2856 - 2870. (13th International Conference on Greenhouse Gas Control Technologies, GHGT-13, 14-18 November 2016, Lausanne, Switzerland) doi: https://doi.org/10 $.1016 /$ j.egypro.2017.03.1406

Williams, J. D. O., Fellgett, M. W., \& Quinn, M. F. (2016). Carbon dioxide storage in the captain sandstone aquifer: determination of in situ stresses and fault-stability analysis. Petroleum Geoscience, 22(3), 211-222. doi: 10.1144/petgeo2016-036

Withjack, E. (1988). Computed tomography for rock-property determination and fluid-flow visualization. SPE Formation Evaluation, 3(04), 696-704. doi: 10.2118/16951-pa

Wolff, M., Flemisch, B., \& Helmig, R. (2013). An adaptive multiscale approach for modeling two-phase flow in porous media including capillary pressure. Water Resources Research, 49(12), 8139-8159. doi: 10.1002/2013wr013800

Yan, W., Zhao, G.-Y., Chen, G.-J., \& Guo, T.-M. (2001). Interfacial Tension of (Methane + Nitrogen) + Water and (Carbon Dioxide + Nitrogen) + Water Systems. Journal of Chemical \& Engineering Data, 46(6), 1544-1548. doi: 10.1021/je0101505

Yang, Z., Tian, L., Niemi, A., \& Fagerlund, F. (2013). Upscaling of the constitutive relationships for $\mathrm{CO}_{2}$ migration in multimodal heterogeneous formations. International Journal of Greenhouse Gas Control, 19, 743-755. doi: 10.1016/j.ijggc.2012.11.015

Yeh, T.-C. J., Gelhar, L. W., \& Gutjahr, A. L. (1985). Stochastic analysis of unsaturated flow in heterogeneous soils: 3. observations and applications. Water Resources Research, 21 (4), 465-471. doi: 10.1029/WR021i004p00465

Zhou, D., Fayers, F. J., \& Orr, F. M. (1994). Scaling of multiphase flow in simple heterogeneous porous media. Proceedings - SPE Symposium on Improved Oil Recovery, 2, 559-569. doi: 10.2118/27833-pa 